\title{
On-line/ Off-line: relação corpo, espaço e masculinidades de homens que buscam parceiros do mesmo sexo no App Tinder no município do Rio Grande - RS.
}

\author{
On-line/ Off-line: la relación cuerpo, espacio y masculinidades de \\ hombres que buscan parejas del mismo sexo en el App Tinder en el \\ municipio de Rio Grande - RS.
}

\author{
On-line/ Off-line: the relationship body, space and masculinities of men \\ seeking same sex couples in the App Tinder in the municipality of Rio \\ Grande - RS.
}

Diego Miranda Nunes ${ }^{1}$

\begin{abstract}
Resumo
O estudo é resultado em andamento da pesquisa de mestrado em Geografia, objetiva apresentar a relação corpo, espaço e masculinidades de homens que buscam parceiros do mesmo sexo no aplicativo Tinder, no município do Rio Grande - RS. Aferimos que o corpo se constituiu como um tema raro na Geografia até o século XXI, a partir disso passa a ser considerado como um elemento geográfico, na medida que se compreende que o espaço não é produzido por sujeitos neutros. Para entender esta relação, foram aplicados questionários semiestruturados online a 154 homens, além da realização de cinco entrevistas em profundidade. Apontamos, a partir de primeiros olhares, que o corpo é um importante dispositivo no espaço virtual, capaz de ser um determinante na busca por relações afetivo-sexuais e na produção de novas sociabilidades gays nos diferentes espaços. Aferimos que as masculinidades dos sujeitos entrevistados estão interpeladas pelos espaços que ocupam e, atravessadas pelos modelos hegemônicos impostos pela sociedade. Por fim, apontamos que os resultados são preliminares, limitados as nossas imersões e primeiras análises.
\end{abstract}

Palavras-Chave: Aplicativo Tinder; Corpo; Espaço; Gênero; Masculinidades.

\section{Resumen}

El estudio es resultado en curso de la investigación de maestría en Geografía, objetiva presentar la relación cuerpo, espacio y masculinidades de hombres que buscan parejas del mismo sexo en la aplicación Tinder, en el municipio de Rio Grande - RS. Aferimos que el cuerpo se constituyó como un tema raro en la Geografía hasta el siglo XXI, a partir de eso pasa a ser considerado como un elemento geográfico, en la medida que se comprende que el espacio no es producido por sujetos neutros. Para entender esta relación, se aplicaron cuestionarios semiestructurados en línea a 154 hombres, además de la realización de cinco entrevistas en profundidad. A partir de las primeras miradas, el cuerpo es un importante dispositivo en el espacio virtual, capaz de ser un determinante en la búsqueda de relaciones afectivo-sexuales y en la producción de nuevas sociabilidades gays en los diferentes espacios. Aferimos que las masculinidades de los sujetos entrevistados están interpeladas por los espacios que ocupan y, atravesadas por los modelos hegemónicos impuestos por la sociedad. Por último, señalamos que los resultados son preliminares, limitados a nuestras inmersiones y primeros análisis

Palabras claves: Aplicación Tinder; Cuerpo; Espacio; Género; Masculinidades.

\begin{abstract}
The study is an ongoing result of the master's degree in Geography, aiming to present the body, space and masculinities relationship of men seeking same sex partners in the Tinder application, in the city of Rio Grande RS. We can see that the body was constituted as a rare theme in Geography until the XXI century, from there it is considered as a geographical element, insofar as it is understood that space is not produced by neutral subjects.
\end{abstract}

\footnotetext{
${ }^{1}$ Mestrando do Programa de Pós-graduação em Geografia - Universidade Federal do Rio Grande - Rio Grande / RS, Brasil.diego_rgnunes@yahoo.com.br
} 
To understand this relationship, 154 semi-structured online questionnaires were applied to 154 men, in addition to five in-depth interviews. We point out, from first glances, that the body is an important device in virtual space, capable of being a determinant in the search for affective-sexual relations and in the production of new gay sociabilities in different spaces. We note that the masculinities of the subjects interviewed are interpellated by the spaces they occupy and, crossed by the hegemonic models imposed by society. Finally, we point out that the results are preliminary, limited to our immersions and first analyzes.

Keywords: Tinder Application; Body; Space; Gender; Masculinities.

\section{Introdução}

$\mathrm{O}$ avanço tecnológico, com início no século $\mathrm{XX}$, trouxe diversas contribuições para a sociedade. Em 1945, surgiram os primeiros computadores nos Estados Unidos e na Inglaterra, sendo ponto de partida à ascensão informacional. Do pós-guerra ao século XXI, as formas de expressão dos relacionamentos afetivo-sexuais também mudaram, passou-se de cartas apaixonadas e longos telefonemas para uma explosão de aplicativos, fazendo com que os sujeitos fossem atravessados por essa onda tecnológica e, por vezes, condicionados a viver nesses espaços virtuais de forma imperativa.

Fazer check-in, marcar pessoas em fotos, realizar compras pela internet, ter diversos grupos sociais em espaços virtuais, possuir uma pluralidade de aplicativos, tudo isso são apenas alguns traços da sociedade contemporânea, cada vez mais plugada e sem fio. A tecnologia atravessou gerações, ligando desde as pessoas mais novas à terceira idade. Os nativos e/ou imigrantes digitais estão agora preocupados com seus smartphones, ainda de manhã já são acordados pelo alarme do celular, aproveitam para ver a temperatura e se atualizam das principais notícias do dia, antes mesmo de saírem da cama.

Os imigrantes digitais precisaram adaptar-se ao novo modo de se relacionar, agora em rede e conectados. A geração nascida ainda no século $\mathrm{XX}$ não vivenciou de forma tão imperativa a onda tecnológica como os nascidos a partir dos anos 2000. E isso se torna ainda mais importante de ser analisado na relação com os homens que buscam parceiros do mesmo sexo e a relação do corpo, espaço e masculinidades. Os estudos sobre corpo e espaço se constituiu como um tema raro na Geografia até o século XX, e as masculinidades se tornam temas potentes de investigação no campo geográfico à medica que se compreende existir diversas feminilidades.

Neste sentido, o artigo tem por objetivo, apresentar os homens que buscam parceiros do mesmo no sexo no aplicativo Tinder em Rio Grande - RS, e como lidam com a relação entre corpo e espaço, num primeiro momento. E como as masculinidades são produzidas no espaço virtual do Tinder, entendendo que existem diferentes masculinidades em variados espaços, produzidas por sujeitos que não são neutros, atravessados por marcadores de raça, 
etnia, gênero, geração e etc. Assim, as seções que seguem estão divididas em: espacialidades de homens que buscam parceiros do mesmo sexo no App Tinder; Masculinidades e corporeidades; Caminhos metodológicos; Alguns apontamentos: para não concluir.

\section{Espacialidades de homens que buscam parceiros do mesmo sexo no App Tinder}

Inicialmente se faz necessário apontar que os conceitos de espaço e corpo estão totalmente atravessados por olhares do campo geográfico, neste sentido, compreendemos que existam apontamentos de outras áreas do conhecimento, porém tentamos nos deter na Geografia com alguns diálogos potentes entre diversas áreas.

É importante compreender que o espaço do aplicativo Tinder produz comunicação, quer entre sujeitos ou com a rede mundial de computadores. O aplicativo é "habitado" por pessoas, sentimentos e desejos que nele projetam um espaço potente para relações homoeróticas. Diante disso, o espaço virtual se torna um território de práticas espaciais, representações e significados. Para Raffestin (1993) essas relações sociais materializam o território e produzem territorialidades. E tais territorialidades estão relacionadas as formas de organização das pessoas no espaço, como se apropriam dele e denotam significados (SACK, 1986).

Os conceitos de territórios e territorialidades aqui abordados, seguem caminhos teórico-metodológicos, entendendo que existem compreensões diversas sobre estes conceitos, a partir da concepção de alguns/as autores/as. Para tanto, optamos por seguir os conceitos propostos por Claude Raffestin, Robert David Sack e Rogério Haesbaert, principais interlocutores.

Assim o atravessamento do conceito de espaço se faz presente ao longo da escrita, entendendo-o como indissociável do território, apesar de se distinguirem epistemologicamente e ontologicamente (SAQUET, 2005). A compreensão do espaço geográfico, como um território de táticas, é necessária uma vez que o aplicativo Tinder permite que os sujeitos se usem de técnicas para moldar suas afetividades. Ou seja, as relações presentes no espaço do App são refletidas no cotidiano e vida das pessoas. Para Saquet $(2015$, p. 38) “[...] o território é uma construção social, histórica, relacional e está sempre vinculado a processos de apropriação e dominação do espaço e, evidentemente, às pessoas $[\ldots] "$.

Com isso, pensando a partir das ideias de Saquet, podemos compreender que a apropriação do espaço territorializa as relações sociais, seja pelas regras e normas ou pelas 
técnicas e tecnologias. O aplicativo Tinder seria isso, a apropriação de um espaço virtual, já concebido na ciência geográfica, fruto de intensos conflitos e rugosidades, sendo dinâmico e podendo ser desterritorializado por diferentes interesses. Pensando a partir de Haesbaert (2014) que paradoxalmente reduzimos a distância física, a partir do virtual, concomitantemente a relação tempo-espaço foi (re)configurada, tornando-se emergente a potencialização de um espaço, que hoje conhecemos como ciberespaço, produzido a partir da multiplicidade e velocidade das tecnologias.

Para Saquet (2015) a própria formação das redes de comunicação influencia diretamente na formação dos territórios. Com isso, "os territórios resultam do processo de construção histórica do e no espaço" (SAQUET, 2015, p. 42). A partir das ideias do autor, entendemos que o território é resultado das relações entre sociedade e natureza interpelados pelos processos de territorialização.

A partir de Raffestin (1993) pensamos o território como resultado da territorialização do espaço, na concepção do autor, o território só existe a partir do espaço. "Ao se apropriar de um espaço, concreta ou abstratamente (por exemplo pela representação), o ator territorializa o espaço (RAFFESTIN, 1993, p. 143). Neste sentido, o território adquire um caráter de práticas, e o Tinder é isso, marcado por relações de poder, com isso as representações neste espaço oportunizam a produção de nós e a construção de redes (RAFFESTIN, 1993).

Os aplicativos virtuais são territórios, instituídos pelas relações sociais e representações dos sujeitos, os limites destes podem ser negociados (coletivamente) ou impostos (individualmente). Sendo assim, se território é poder em Raffestin, analogamente trazemos o Biopoder de Foucault, como àquele poder sobre a vida dos sujeitos que estão imersos nos aplicativos em troca de uma pseudo-segurança para negociar suas vivências e táticas homoeróticas.

Compartilhamos das ideias de Robert Sack em seu livro publicado em 1986 denominado "Territorialidade Humana", para iniciar a discussão sobre territorialidades e também utilizamos Rogério Haesbaert, para compreender os processos de multiterritorialidades, sempre buscando defender o espaço virtual como um território de possibilidades táticas, possíveis de sociabilidades. Para SACK (1986),

A Territorialidade nos humanos é melhor entendida como uma estratégia espacial para afetar, influenciar ou controlar fontes e pessoas, controlando área; e, como uma estratégia, a Territorialidade pode ser ligada e desligada. Em termos geográficos ela é uma forma de comportamento espacial (SACK, 1986, p. 3). 
Com isso, Sack nos coloca a pensar sobre as estratégias espaciais de controle, entendendo assim que o espaço do App Tinder é também um campo de possibilidades de controle sobre os sujeitos. Para o autor, a territorialidade é um componente geográfico potente para entender como a sociedade e o espaço se comportam, a partir da relação de interconexão. Enfatizando que "Territorialidade [...] é um uso sensato historicamente do espaço. Especialmente, uma vez que ela é socialmente construída e depende de quem está controlando quem e porque" (SACK, 1986, p. 5). Sendo assim, a territorialidade é carregada de relações de poder, influenciando diretamente o grupo social, a parir de acordos, sentimento de pertencimento e culturas que produzem identidades territoriais.

Como afirma Saquet (2015) as territorialidades estão em constantes transformações em relação ao espaço-tempo, e isso acarreta em alterações dos territórios, entendendo que estes são substantivados a partir de desigualdades, identidades, mudanças e diferenças. A territorialidade no Tinder, se comporta pautadas nas ideias de Sack e Saquet, sendo dinâmicas resultados do processo de informatização e potencialização das mídias sociais, e também produtor de relações dos sujeitos, táticas e usos do espaço virtual como um espaço potente para conquistar parceiros. Como afere Saquet (2015),

As territorialidades (econômicas, políticas e culturais) são, simultaneamente, resultado, condicionantes e caracterizadoras da territorialização e do território num movimento contínuo de desterritorialização e reterritorialização: as relações sociais, as apropriações e as demais práticas espacio-temporais,ou seja, as territorialidades determinam cada território, influenciando ao mesmo tempo, a sua própria reprodução (com rupturas e permanências), a partir do território formado, isto é, são influenciadas pelo território em cada relação espaço-tempo (SAQUET, 2015, p. 45).

Com isso, as práticas espaciais, são também temporais. A partir de Saquet (2015, p. 107) “vivemos as processualidades territoriais-espaciais-temporais simultaneamente". Para Saquet (2009), esta territorialidade é compreendida “[...] como um processo de relações sociais, tanto econômicas, como políticas e culturais de um indivíduo ou de um grupo social" (p. 8) que correspondem “[...] às relações sociais e às atividades diárias que os homens têm com sua natureza exterior" (p. 8).

Sendo assim, o autor enfatiza que a territorilialidade é o processo de produção do território, sendo essencial para a vida cotidiana e a construção da identidade. Entendendo assim, que essa identidade é produzida a partir das múltiplas relações que estabelecemos com as territorialidades, envolvendo os espaços materiais e imateriais, desde crenças a valores. Para Haesbaert (2014, p. 64), a territorialidade [...] não é apenas "algo abstrato" num sentido que muitas vezes se reduz ao caráter de abstração analítica, epistemológica. Ela é também 
uma dimensão imaterial [...] e pode inserir-se eficazmente como uma estratégia políticocultural $[\ldots] "$.

Neste sentido, entendemos que a multiterritorialidade contemporânea é um processo, resultado do novo aparato-tecnológico informacional, a capacidade que temos de estar conectados/as em rede, nos permite pensar na integração de novos territórios e territorialidades. Dito isso, Haesbaert (2014) afirma:

\begin{abstract}
A multiterritorialidade contemporânea inclui assim uma mudança não apenas quantitativa - pela maior diversidade de territórios que se colocam a nosso dispor (ou pelo menos das classes e grupos mais privilegiados) -, mas também qualitativa, na medida que temos hoje a possibilidade de combinar de uma forma inédita a intervenção e, de certa forma, a vivência, concomitantemente, de uma enorme gama de territórios e/ou territorialidades (HAESBAERT, 2014, p. 79).
\end{abstract}

Vivenciar as múltiplas formas territoriais, fazem parte da sociedade contemporânea, onde a distância física parece ter pouco significado. O Tinder é um exemplo, a conversação em rede delimitado por um raio de $161 \mathrm{~km}$, faz do aplicativo um território-rede, podendo assim serem usufruídas as (multi)territorialidades. Para Haesbaert (2004) território e rede não são dicotômicos, uma vez que a rede constitui o território. Ainda, segundo o autor, seriam as novas mobilidades espaciais que conceituariam o que o Haesbaert entende por território-rede. Compreendendo assim, como mais flexíveis, importando com isso, o acesso "[...] aos meios que possibilitem a maior mobilidade física dentro da(s) rede(s), ou os pontos de conexão [...] com as múltiplas territorialidades [...]” (HAESBAERT, 2014, p. 81).

O território se constitui em movimento, num processo de territorializar-se "significa também, hoje, construir e/ou controlar fluxos/redes e criar referenciais simbólicos num espaço em movimento, no e pelo movimento" (HAESBAERT, 2004, p. 280). Sendo assim o territóriorede caracteriza-se justamente pelo caráter móvel do território, ou ainda, pelas trocas fomentadas pela interconexão virtual, principalmente na sociedade contemporânea, num processo de caráter territorializador e desterritorializador, com isso a rede não anula o território.

\footnotetext{
Para nossos propósitos, a característica mais importante das redes é seu efeito concomitantemente territorializador e desterritorializador, o que faz com que os fluxos que por elas circulam tenham um efeito que pode ser ora de sustentação, mais 'interno' ou construtor de territórios, ora de desestruturação, mais 'externo' ou desarticulador de territórios (HAESBAERT, 2004, p. 294).
}

Sendo assim, para o autor, a partir da perspectiva de ser e estar simultaneamente em diversos territórios, constituem a multiterritorialidade. O domínio das redes e dos fluxos de mobilidade, permite que a sociedade contemporânea esteja cada vez mais conectada em diversos lugares. Como mencionado anteriormente, as barreiras físicas não são mais 
problemas, o meio virtual proporciona a vivência de múltiplas territorialidades e construções e representações em novos territórios. Em suma, a sociedade contemporânea vivencia novas práticas espaciais, oportunizadas pelo virtual, mas também pelas táticas de apropriação do território.

Dito isso, o Tinder se constituiu enquanto um território passível de uma apropriação, territorializando-se e se configurando como espaço virtual potente para expressar afetividades. Os sujeitos se apropriam do Tinder em busca de sanar seus desejos e vontades, com isso configura-o como um território de resistência, a partir da visibilidade homossexual, referindose a homens que buscam parceiros do mesmo sexo. Mas também é configurado como um território de práticas espaciais, passível de representações dos corpos e das masculinidades.

\section{Masculinidades e corporeidades}

Optamos por pensar as masculinidades a partir de regimes de visibilidades/invisibilidades, construídas e moldadas a partir de regulações e interesses específicos de homens que buscam parceiros do mesmo sexo. Neste sentido, é interessante, num primeiro momento, refletir sobre o que constitui o "ser homem" e quais atributos este deve possuir para ser aceito a partir dos limites impostos pela sociedade.

Assim, fazendo um resgate histórico das masculinidades, no plural, por compreender que existem múltiplas e diversas, Conell (1995) em Políticas de Masculinidades aponta que "há uma consciência gradualmente crescente sobre a possibilidade de mudança nas relações de gênero. Essa consciência surgiu nos Movimentos de Liberação das Mulheres, de Liberação dos Gays e de Liberação dos Homens, nos anos 70" (CONELL, 1995, p. 186). Dissertando que, na década de 70, ou a partir dela, criticava-se a "noção de papel masculino", pois a maioria dos críticos acreditava que a masculinidade estava passando por uma crise a partir desses movimentos.

Segundo o Conell (1995), as masculinidades têm a ver com as práticas e com o meio social, existindo tensões nas formas como se deve agir e andar, ou seja, um conjunto de "regulações". Segundo Conell, é importante destacar dois pontos para pensar a complexidade das masculinidades,

Em primeiro lugar, diferentes masculinidades são produzidas no mesmo contexto social; as relações de gênero incluem relações entre homens, relações de dominação, marginalização e cumplicidade. Uma determinada forma hegemônica de masculinidade tem outras masculinidades agrupadas em torno dela. Em segundo lugar, qualquer forma particular de masculinidade é, ela própria, internamente complexa e até mesmo contraditória. Devemos essa compreensão especialmente a Freud, que enfatizava a presença da feminilidade dentro da personalidade dos 
homens e da masculinidade dentro da personalidade das mulheres e que analisou os processos de repressão pelos quais essas contradições são tratadas. Mas ela surge igualmente em outros contextos (CONELL, 1995, p. 189).

Assim, destaca-se que, ao longo da construção do "ser homem", os sujeitos são atravessados por uma série de códigos e condutas, ainda no âmbito familiar, que devem ser seguidas. Essas interpelações se dão como forma de distanciamento do "ser mulher" e, assim, afasta-se de uma feminilidade, o que, num primeiro momento, seria compreendida como opostos. Ou seja, a constituição da masculinidade perpassa para além dos desejos e das vontades, ela é produzida e construída a partir de determinadas sociedades e de um dado momento histórico. Conell (1995) salienta que,

\begin{abstract}
se as masculinidades são construídas através dessas formas, elas são também constantemente re-construídas. As masculinidades estão constantemente mudando na história. Obviamente, podemos não vivenciá-las como tais; a ideologia popular freqüentemente representa o gênero como aquilo que não muda: o estável e "natural" padrão que subsiste sob o fluxo geral. O padrão agora frequentemente chamado de "masculinidade tradicional", e vinculado à "família tradicional", é, na verdade, uma forma de gênero historicamente recente, um produto claro do mundo moderno (CONELL, 1995, p. 191).
\end{abstract}

Dizer que existe um padrão é presumir que existem masculinidades hegemônicas e masculinidades subordinadas, entendendo elas como práticas e identidades, por vezes dinâmicas. Segundo Conell e Messerschmidt,

o conceito de masculinidade é criticado por ter sido enquadrado no seio de uma concepção heteronormativa de gênero que essencializa a diferença macho-fêmea e ignora a diferença e a exclusão dentro das categorias de gênero. Ao conceito de masculinidade é atribuído o fato de esse permanecer logicamente numa dicotomização do sexo (biológico) versus gênero (cultural), dessa forma marginalizando ou naturalizando o corpo (CONELL e MESSERSCHMIDT, 2013, p. 250).

Os movimentos feministas atrelados ao movimento gay dos anos 1970 fomentam as discussões sobre as masculinidades. Quadrado (2012, p. 43) afirma que, "a partir desses movimentos, as políticas identitárias masculinas começaram a ser problematizadas, adotandose o entendimento de que a dominação masculina se dava, também, sobre os homens, e não apenas sobre as mulheres". A lógica de dominação tenciona relações de poder. "As masculinidades constituem posições de sujeito, possíveis de serem ocupadas em determinado contexto cultural e histórico, instituídas em relações assimétricas de poder" (QUADRADO, 2012, p. 44). As masculinidades são produzidas (moldadas) a partir do espaço que as constituem, seja a escola, seja a residência, seja a igreja (como religião). Sob a visão da mesma autora, 
cada sujeito produz sua masculinidade a partir das tensões, fraturas e assujeitamentos que se dão entre o modelo de masculinidade considerado hegemônico no sistema de relações de gênero no qual se encontra imerso e as diversas outras formas de masculinidade com as quais se confronta (QUADRADO, 2012, p. 45).

A partir da autora podemos entender que as relações mediadas pela internet, em específico nos aplicativos de busca por parceiros, reforçam e produzem distintas masculinidades. Uma masculinidade hegemônica é visível nesses espaços virtualizados, inclusive nas descrições de perfis masculinos homossexuais. Quadrado (2012) enfatiza que as mídias reforçam modelos de masculinidades, compreendendo que estes são atravessados por valores e códigos de condutas específicas.

Atravessados nas questões de masculinidades está a relação com o corpo, neste sentido compreendemos assim como Goellner (2003) que refletir sobre a produção dos corpos interpelados pela cultura moderna é um desafio para os/as pesquisadores, porém, um exercício importante a ser realizado. O corpo é histórico, produto de uma construção social, que apresenta marcas no espaço e no tempo. Assim, o espaço é um resultado de sujeitos que não são neutros, como afirma Silva (2011), mas produto de corpos interpelados por marcadores como gênero, raça, etnia e geração.

Portanto para Goellner (2003) o corpo é muito mais do que aquilo que vemos, ele é produto da linguagem. Assim, é importante refletir sobre os espaços, pois para a autora estes educam os corpos e deixam marcas que nele são incorporados. Com isso, pensamos nestes corpos situados em um determinado tempo e espaço, sendo este o virtual. E neste sentido, pensamos que estes corpos não estão prontos, dados, eles são múltiplos, plurais e carregados de significados. Para Goellner (2010) o corpo revela o tempo e espaço que foi educado, compreendendo assim que este é pedagogizado por processos contínuos. É pelo corpo que as pessoas ocupam e vivem as redes sociais.

O culto ao corpo está cada vez mais presente na contemporaneidade, a mídia tem o seu papel de difusora, principalmente a partir do aprimoramento da internet. Para Miskolci (2006), "o culto ao corpo levou ao incremento de um individualismo perverso, no qual cada um se torna o responsável pelo que é de forma que sua condição física é diretamente atribuída à sua capacidade de autodisciplina" (p. 682). Ao longo da história sempre foram demarcados padrões de corpos e, consequentemente, de masculinidades. Os filmes sempre colocam os guerreiros e lutadores como padrões de corpos idealizados e como masculinidades hegemônicas a serem seguidas. Para Miskolci (2006),

somente aqueles que se submetem aos ideais hegemônicos podem querer incorporálos no sentido mais literal, ou seja, por meio de todas as técnicas, exercícios e drogas 
que objetivam adequar suas formas corporais ao modelo socialmente imposto de masculinidade (MISKOLCI, 2006, p. 684).

Isso significa que a busca pelo corpo da mídia é possível, pelo disciplinamento e uso de outros elementos que nos são caros à vida moderna e nem todos/as conseguem. Para Miskolci (2006), para “o processo de assujeitamento psíquico-corporal a palavra-chave é adequação. Fazer parte de um grupo ideal é o principal objetivo dos praticantes de musculação, dos consumidores de anabolizantes e hormônios diversos (p. 684). Assim, quem não possuir um corpo trincado, bronzeado e em forma é tido como alguém fracassado.

O corpo gordo, segundo os padrões, é tido como inadequado e o sujeito com tal característica é excluído desses grupos sociais. Para Miskolci (2006), "gera subjetividades autodestrutivas em sua busca de adequação a qualquer custo. Em alguns casos, o medo da rejeição supera até mesmo o desejo de sobreviver" (p. 685). Então, a procura por procedimentos médicos como cirurgias plásticas é vista como um meio para conseguir um corpo ideal e assim superar as fronteiras da ordem social.

\section{Caminhos metodológicos}

O estudo mesclou dados qualitativos e quantitativos com aplicação de um questionário semiestruturado on-line a 154 homens e entrevistas em profundidade feita com cinco homens que buscam parceiros do mesmo sexo no App Tinder, a partir da inserção do pesquisador na plataforma digital. Essa metodologia de produção dos dados permite uma maior aproximação com o objeto de pesquisa, bem como possibilita uma interação entre pesquisador e entrevistados, permitindo aos sujeitos de pesquisa certo conforto na hora de expor suas respostas, não ficando restritos a respostas do tipo "sim e não".

O questionário on-line foi aplicado aos homens que se encontravam dentro de um raio de $31 \mathrm{~km}$ a partir da Universidade Federal do Rio Grande, este nos possibilitou caracterizar o universo de homens que se encontravam no aplicativo Tinder no período de 19 de fevereiro de 2018 à $1^{\circ}$ de março do mesmo ano.

As entrevistas em profundidade nos ajudam a pensar na relação corpo, espaço e masculinidades, apontadas pelo questionário e verbalizadas nos discursos dos sujeitos entrevistados. E para analisar os discursos utilizamos a Análise do Discurso da Escola Francesa de Michel Pêcheux.

A partir da $\mathrm{AD}$, compreendemos o que tem por trás daquilo que é falado, ou seja, perceberemos os sujeitos “despidos”, não importando a língua fechada, como afirma Orlandi (2013), mas sim a dimensão do homem e da mulher no contexto social em que estão postos. 
Com isso, a AD nos dá liberdade para analisar aquilo que foi dito em determinado espaço e aquilo que não foi dito e, por consequência, poderia ser verbalizado em outros espaços.

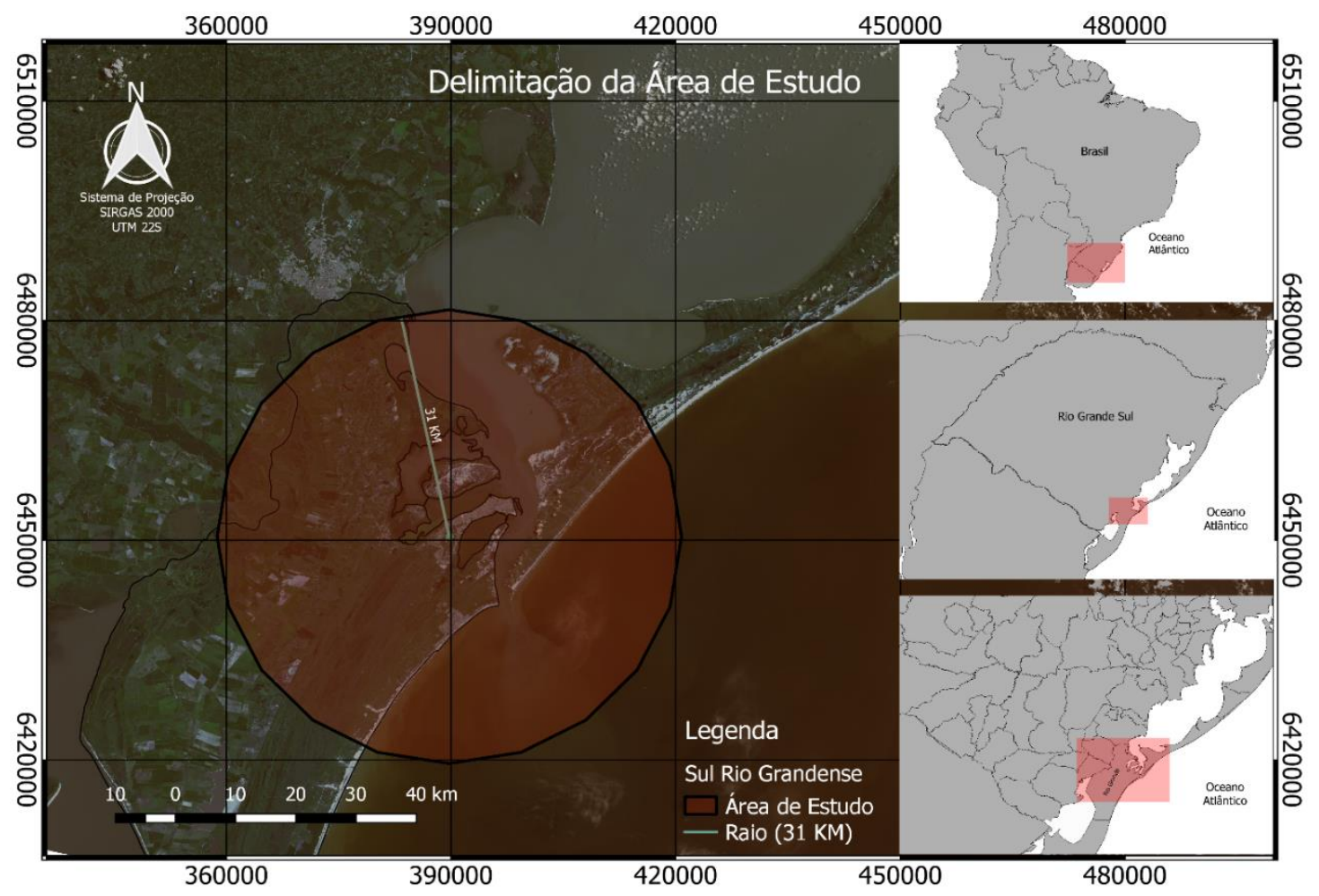

Figura 1: Delimitação da área de estudo

Fonte: Sistema de Projeção Sirgas 2000. Elaborado por Ítalo Seilhe Reis, 2018.

\section{Alguns apontamentos: para não concluir}

A partir da aplicação do questionário semiestrutrurado on-line elaborado pelo Google Forms e aplicado a 154 homens, apontamos que são jovens, entre 18 e 24 anos, correspondendo a 54\% daqueles que responderam o questionário. São predominantemente brancos, apontamos como prévia as opções: branca; preta; amarela; parda e indígena. Dos 154 usuários, 104 se autodeclararam brancos, correspondendo 67\%, 24 pretos, 26 pardos, as opções amarelos e indígenas não apresentaram nenhuma resposta. Estas delimitações prévias vão ao encontro dos caminhos metodológicos estipulados pelo IBGE.

Além disso, quando questionados sobre quem sabe das suas orientações sexuais, $54 \%$, correspondente a 83 usuários, dizem que todos/as sabem; 5\% respondem que a família sabe, 
referente a sete respostas dessa fatia. Ainda, $8 \%$ dizem que apenas amigos/as sabem da sua orientação, sendo um total de 12 respostas. Ainda, com $30 \%$ representando 47 respostas, encontramos os usuários que relataram que família e amigos/as sabem da sua orientação sexual, e apenas $1 \%$ diz que ninguém sabe deles, um total de duas respostas. Percebemos que, se somarmos as duas maiores porcentagens, "todos/as" e "família e amigos/as" totaliza 84\%, o que nos indica que os usuários que responderam o questionário, em sua maioria, lidam de forma aberta com a sua orientação sexual.

Com relação a escolaridade, cinco usuários possuem ensino fundamental incompleto, seis possuem ensino fundamental completo, 15 têm ensino médio incompleto e 35 possuem ensino médio completo. Sete disseram possuir ensino técnico, 46 possuem ensino superior incompleto, 22 dizem ter ensino superior completo e 18 pós-graduação. E sobre a religiosidade, 82 responderam possuir algum tipo de religião. A partir das 82 respostas, notamos que $6 \%$ disseram ser evangélicos, correspondendo a cinco respostas; $6 \%$ afirmaram serem cristãos, também um total de cinco respostas; $12 \%$ eram católicos, equivalente a dez usuários. Ainda, a maior fatia do gráfico, 50\%, representando 41 respostas, alegou ser oriunda de religiões de matriz africana. E 26\% disseram serem espíritas, um total de 21 respostas.

Quando questionados sobre existir um tipo de homem mais procurado no aplicativo Tinder, 79\% relatam que sim, existem homens mais procurados no app, correspondendo a 122 respostas. E $21 \%$ dizem que não, totalizando 32 usuários que acreditam que não existe um ideal de homem nesse espaço virtual. E, quando questionados sobre existir um tipo de corpo mais procurado no aplicativo Tinder, $84 \%$ relatam que sim, existe um tipo de corpo mais procurado no app, correspondendo a 130 respostas. E $16 \%$ dizem que não, totalizando 24 usuários que acreditam que não existe um ideal de corpo.

Assim, caminhamos para o segundo momento metodológico, o qual foi a entrevista com cinco homens, trazemos aqui uma breve análise dos discursos produzidos pelos sujeitos, aferindo que a pesquisa ainda se encontra em andamento e, neste sentido, os dados precisam ser combinados com o quantitativo. Os conceitos norteadores da análise foram: espacialidades, masculinidades e corporeidades.

Sobre o conceito de espacialidades, a partir do discurso dos sujeitos e dos questionamentos que fizemos, percebemos que de modo geral os sujeitos entrevistados compreendem o espaço virtual como um território para estabelecer laços, sejam eles afetivo ou sexuais. Entendem o espaço virtual como potente de práticas, sejam elas amizades, relacionamentos e sexo. Além disso, o virtual se torna um meio técnico para a materialização dos encontros de homens que buscam parceiros do mesmo sexo. 
Sobre o conceito de masculinidades, os sujeitos entrevistados afirmam existir um tipo de homem mais procurado no espaço do Tinder. Assim, de modo geral, atribuem características como, fortes, reservados e não afeminados. E estas estão presentes nos discursos sujeitos entrevistados por medo de preconceitos da sociedade.

Sobre o conceito de corporeidades, de um modo geral, percebemos que os discursos dos sujeitos estão marcados pela norma. Eles entendem que existe um tipo de corpo mais procurado no aplicativo Tinder e este é regulado por normas impostas pela sociedade. Corpos magros, sarados e em forma são os mais desejados, em contrapartida corpos que são disformes do padrão sofrem preconceito nos espaços virtuais. Neste sentido existe uma convergência de insatisfação com o próprio corpo dos sujeitos entrevistados ao mesmo tempo que apontam que mudariam algo neles.

Com isso, compreendemos nas nossas análises preliminares que a relação corpo, espaço e masculinidades estão regulados pela heteronormatividade, seja no espaço online ou no espaço off-line. Assim, os sujeitos são atravessados pelos espaços que produzem e circulam. O aplicativo Tinder é um espaço regulado, pela norma, pelas regras tão iguais quanto a dos espaços físicos de sociabilidades gays.

\section{Referências}

CONELL, Robert. MESSERSCHMIDT, James. Masculinidade hegemônica: repensando o conceito. Revista Estudos Feministas, Florianópolis, v. 21, n. 1, pp. 241 - 282, Jan. / Abr. 2013. Disponível em: < https://periodicos.ufsc.br/index.php/ref/article/view/S0104026X2013000100014/24650> Acesso em: 05/10/2018.

CONNELL, Robert W. Políticas da masculinidade. Educação \& Realidade. Porto Alegre, v. 20, n. 2, jul./dez., p. 185-206, $1995 . \quad$ Disponível em: < http://www.seer.ufrgs.br/educacaoerealidade/article/view/71725> Acesso em: 22/10/2018.

GOELLNER, Silvana Vilodre. "A produção cultural do corpo." In: LOURO, Guacira Lopes; NECKEL, Jane Felipe; GOELLNER, Silvana Vilodre. (Orgs.) Corpo gênero e sexualidade: um debate contemporâneo. Petrópolis, Vozes, 2003.

HAESBAERT, Rogério. Viver no limite: território e multi/transterritorialidade em tempos de in-segurança e contenção. Rio de Janeiro: Bertrand Brasil, 2014.

HAESBAERT, Rogério. 2004. O mito da desterritorialização: do "fim dos territórios" à multi-territorialidade. Rio de Janeiro: Bertrand Brasil.

MISKOLCI, Richard. Corpos elétricos: do assujeitamento à estética da existência. Revista de Estudos Feministas,v. 14 n.3 Set/Dez, Florianópolis - SC, 2006. Disponível em: < 
http://www.scielo.br/scielo.php?pid=S0104-

026X2006000300006\&script=sci_abstract\&tlng=pt> Acesso em: 20/04/2018.

ORLANDI, Eni P. Análise De Discurso - Princípios e procedimento. Campinas/SP: Ed. 11. Pontes Editores, 2013

QUADRADO, Raquel. PRÁTICAS BIOASCÉTICAS CONTEMPORÂNEAS: notas sobre os corpos masculinos nas comunidades que discutem cirurgia plástica na rede social Orkut. 2012. Tese (Doutorado em Educação em Ciências) - Instituto de Educação, Universidade Federal do Rio Grande - FURG, Rio Grande, 2012.

RAFFESTIN, C. Por uma Geografia do Poder. São Paulo: Ática. 1993.

SACK, R. D. Human Territorility - Its Theory and History. Cambridge: Cambridge University Press, 1986.

SAQUET, Marcos Aurélio. Abordagens e concepções de território. São Paulo: Outras Expressões, 2015.

SAQUET, Marcos Aurélio. Entender a produção do espaço geográfico para compreender o território. In: SPOSITO, E. (Org). Produção do espaço e redefinições regionais: a construção de uma temática. Presidente Prudente/SP: FCT/UNESP/GAsPERR, 2005, pp. 35 - 51.

SILVA, Joseli Maria; ORNAT, Marcio Jose. Espaço e múltiplas masculinidades: um desafio para o conhecimento científico geográfico brasileiro. In: SILVA, Joseli Maria; ORNAT, Márcio José; CHIMIN JUNIOR, Alides Babtista. Espaço, gênero \& masculinidades plurais. Ponta Grossa:Todapalavra, 2011, pp. 23 - 54. 